\title{
Quality assurance system of air pollution monitoring network
}

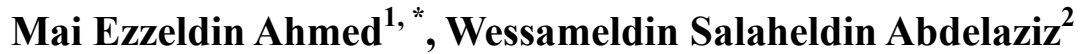 \\ ${ }^{1}$ Environmental Quality Assurance Department, Egyptian Environmental Affairs Agency (EEAA)-Egypt \\ ${ }^{2}$ Laser applications of Metrology Department, National Institute of Laser Enhanced Sciences (NILES), Cairo University- Egypt
}

\section{Email address:}

maie.ahmed@yahoo.com (M. E. Ahmed)

\section{To cite this article:}

Mai Ezzeldin Ahmed, Wessameldin Salaheldin Abdelaziz. Quality Assurance System of Air Pollution Monitoring Network. International Journal of Environmental Monitoring and Analysis. Vol. 1, No. 4, 2013, pp. 133-138. doi: 10.11648/j.ijema.20130104.14

\begin{abstract}
Performa quality assurance system such as applying calibration systems ensures the data will meet defined standards quality with a standard level of confidence.The work represents the way of using the standards to represent the highest level in the traceable chain of calibrations in the environmental monitoring network. The calibration of the Air Quality Monitoring to keep the performance at the confident level 95\%; through determining and documenting the deviation of the indication of a measuring instrument from the true value.
\end{abstract}

Keywords: Environmental Monitoring, Air Pollutants, Calibration, Reference Standards, Gas Cylinders

\section{Introduction}

We describe and implement a quality system complying with the requirements of ISO/IEC 17025: General Requirements for the Competence of Testing and Calibration Laboratories by applying Quality assurance (QA) program. It is a broad plan for maintaining quality in all aspects of a program, establishes the need for quality control (QC). The monitors' calibration is one of this plan tools to adjust the performance of monitoring network and determine the key concepts of QA/QC.

Pollution is the release of waste matter or energy into the environment by man so that it causes damage or deterioration to living systems and/or environment.

A pollutant is any substance brought about by human activities or source of energy which, at an unacceptable level, causes damage to the environment or is harmful to living systems.

The air pollutants include Carbon monoxide (CO), Sulphur dioxide $\left(\mathrm{SO}_{2}\right)$, Nitrogen oxides (NOx), Hydrocarbons (HCs), Ozone $\left(\mathrm{O}_{3}\right)$ and Particulates.

$\mathrm{CO}$ is a poisonous gas, can cause death, combines with haemoglobin in red blood cells to form stable complex, carboxyhaemoglobin.

Sulphur dioxide $\left(\mathrm{SO}_{2}\right)$, causes damage to respiratory systems and increase in asthma attacks. Acid rain - damage buildings, thought to be responsible for the deaths of large numbers of trees in Europe and America.
Nitrogen oxides (NOx), a poisonous gas, that damage lung tissues and blood vessels. Acid rain gives rise to photochemical smog.

Hydrocarbons (HCs)cause photochemical smog.Some hydrocarbons, e.g. benzene, are known carcinogens.

Ozone $\left(\mathrm{O}_{3}\right)$, pollutant Irritates the eyes, makes more serious asthma damages plantsand Particulatesimpair lung function by constricting respiratory passage and damaging lung tissue, cause respiratory disease.Certain particles are suspected to cause cancer

Air pollution monitoring Network is a system of regular time measuring air pollutants by numbers of air stations distributed along different area to represent several conditions like industrial, residential and transportation conditions.

Along the network, the monitoring system subjects to regular QA system to conform to ISO 17025 and apply traceability to IS system.

\section{Methods}

The Gas monitors are calibrated by letting the monitor measure a gas of known concentration. Samplers are calibrated by measuring the air flow through the sampler. These calibrations are performed at the station using working standards, gas cylinder and various flow meters for samplers.

There are three levels of calibration standards:

1. The primary reference standard 
2. The travelling standard

3. The working standard

The primary reference standard represents the highest level in the change of traceability. All calibrations and calibration standards are referenced to the primary standard. The primary standard itself has a reference outside thecountry is imported periodically.

The ideal situation would be to always calibrate the instruments using the reference standard. This would provide the shortest possible chain of traceability. However this is not practical. The reference standard should be kept and operated under strict conditions. A malfunctioning reference standard will affect the entire measurement network. As a result the reference standard should not be taken outside the laboratory except for calibration of the standard itself.

Since the reference standard has to be kept inside the laboratory, working standards are used at the station for periodical calibrations and check of the instrument response. The working standard is of lower quality the reference standard.The accuracy of concentration of travelling gases is $\pm 5 \%$, however the accuracy of concentration of reference gases is $\pm 2 \%$ is used.

The working standard has to be calibrated periodically. A malfunctioning working standard will affect the measurements done at that particular station. The working standard is calibrated periodically by bringing a travelling standard to the station.

The travelling standard is usually of the same quality as the working standard. Before going to the station the travelling standard is calibrated in the laboratory using the primary standard as reference.

The quality control system requires a detailed plan specifying how and when the different calibrations are to take place. In the following, thesystem of calibrations is presented in detail.

\subsection{Analytical Instruments}

- Continuous gas analyzers recorded 5-minute average data. Measurements discussed herein focus on nitrogen oxides $\left(\mathrm{NO}_{2}\right.$ and $\left.\mathrm{NO}_{\mathrm{X}}\right)$. The $\mathrm{NO}_{\mathrm{X}}$ analyzer (Thermo model) used for this study employs chemilluminescence detection for continuous measurement of $\mathrm{NO}, \mathrm{NO}_{2}$, and $\mathrm{NO}_{\mathrm{X}}$. $\mathrm{NO}$ is oxidized to $\mathrm{NO}_{2}$ in the presence of excess ozone $\left(\mathrm{NO}+\mathrm{O}_{3}\right.$ $\mathrm{NO}_{2} *+\mathrm{O}_{2}$ ). During this reaction, light from 500-3000 nm is emitted. The intensity of the light emitted during this reaction is directly proportional to the NO sample concentration. $\mathrm{NO}_{\mathrm{x}}$ is reduced in the presence of a molybdenum catalyst to form NO and measured using the same chemilluminescence detection method.

- The Sulphur Dioxide analyzer delivers precise and reliable performance at accuracy $\pm 10 \%$. It uses pulsed UV fluorescence detection technology to measure $\mathrm{SO}_{2}$ in ambient air. Model: Thermo TEI model $43 \mathrm{C} \mathrm{SO}_{2}$ monitor

- CO Analyzer, Model 48i is The Thermo Scientific* Model 48i CO Analyzer is a gas filter correlation analyzer that measures the amount of carbon monoxide (CO) in ambient air.

- Sequential Ambient Particulate Sampler, The Thermo Scientific is a U.S. EPA Reference Method Ambient Manual Sequential Sampler for both PM-2.5 and PM-10.

- Thermo - Model 146i - Multi-gas Calibrator.Multipoint calibrations in combination with zero and span data are used in evaluating analyzer performance and establishing data validity.

\section{Results and Discussion}

\subsection{Quality Assurance of Gas Monitors}

The quality assurance of gas monitors will be described by following the traceable chain of calibrations starting at its lowest level at the station.

\subsubsection{Zero/Span Checks at the Station}

At the station the zero and span response is checked periodically. This is only a check where the monitor response is observed but no adjustments (calibrations) are made. A working standard is used as reference when performing a zero/span check.

There are at least three types of zero/span check equipment for gas monitors, table 1 .

Table 1: Zero/span check equipment for gas monitors. Automatic systems can be operated manually too. Zero air is generated from ambient air using scrubbers.

\begin{tabular}{lllll}
\hline Monitor & Z/S check & & Period & Operation \\
\hline & Unit & $\mathrm{Gas}$ & & \\
$\mathrm{CO}, \mathrm{CH}$ & Gas cylinder & $\mathrm{CO}$, & & \\
$\mathrm{NO}_{\mathbf{x}}, \mathrm{SO}_{2}$ & was cylinder & $\mathrm{CH}_{4}+\mathrm{C}_{3} \mathrm{H}_{8}$ & Daily & Automatic \\
$\mathrm{O}_{3}$ & $\mathrm{O}_{3}$ generator & $\mathrm{O}_{3}$ & Weekly & Manual \\
\hline
\end{tabular}

The gas cylinder with dilution unit utilizes a high concentration gas cylinder and a one point. Table 2

Table 2: Gas cylinders dilution

\begin{tabular}{lllll}
\hline Span gas & Concentration & Cylinder & \multicolumn{2}{l}{ Single point calibrator } \\
\hline & & volume & Dilution & $\begin{array}{l}\text { Output } \\
\text { conc. }\end{array}$ \\
$\mathrm{SO}_{2}$ & $800 \mathrm{ppb}$ & 10 litre & $\mathrm{X}$ & $800 \mathrm{ppb}$ \\
$\mathrm{NO}$ & $800 \mathrm{ppb}$ & 10 litre & $\mathrm{X}$ & $800 \mathrm{ppb}$ \\
$\mathrm{CO}$ & $450 \mathrm{ppm}$ & 50 litre & $1: 10$ & $45 \mathrm{ppm}$ \\
$\mathrm{CH}_{4}+\mathrm{C}_{3} \mathrm{H}_{8}$ & $(18+2) \mathrm{ppm}$ & 50 litre & $1: 10$ & $(1.8+0.2)$ \\
$\mathrm{O}_{3}$ & $200 \mathrm{ppb}$ & $\mathrm{X}$ & $\mathrm{X}$ & $200 \mathrm{ppb}$ \\
\hline
\end{tabular}

Calibrator dilutes the gas with scrubbed air to a suitable concentration. The unit can also output only scrubbed air for the zero check. The combined gas cylinder and dilution unit is considered to be the working standard.

When a gas cylinder is used with no dilution the cylinder is filled with gas at ambient concentration. The cylinder is 
connected directly to the monitor input port at ambient pressure. Zero air for the zero check is produced using a standalone zero air generator with scrubbers. The gas cylinder is the working standard.

The concentration will depend upon ambient conditions at the site. The $\mathrm{CO}$ and $\mathrm{CH}$ standards are high concentration gas cylinders connected to a dilution unit.

$\mathrm{O}_{3}$-monitors use an internal $\mathrm{O}_{3}$ generator to generate $\mathrm{O}_{3}$.

Table 3.

The zero level is calibrated using scrubbed ambient air.

If the monitor is in working order the calibration actually includes two calibrations. One calibration is performed on the monitor as it is without cleaning or adjusting it. This is done to verify the monitor response after a period of
The $\mathrm{O}_{3}$ is diluted with scrubbed air to a preset level of $\mathrm{O}_{3}$ during the zero/span check. The unit can also output only scrubbed air for the zero check. The $\mathrm{O}_{3}$ generator is the working standard.

\subsubsection{Calibration of Gas Monitors}

Gas monitors are calibrated on several occasions,

operation. Before the second calibration the monitor is cleaned, spare parts changed etc. During the second calibration the monitor response is adjusted if necessary. This calibration is performed to make the monitor ready for a new period of operation.

Table 3: Calibration of gas monitors.

\begin{tabular}{llllll}
\hline Occasion & Calibration & Standard & Location & Period & Institution \\
\hline New & Dynamic & Primary & Mon. Lab & X & Mon. lab \\
Mal-function & Two point & Trav. & Station & X & Mon. lab \\
After repairs & Dynamic & Primary & Mon. lab & X & Mon. Lab \\
Periodically & Two point & Trav. & Station & 3 months & Mon. lab \\
Periodically & Dynamic & Primary & Mon. lab & 1 year & Mon. lab \\
Station audit & Two point & Trav. & Station & 1 year & Ref. lab \\
Audit in the lab & Dynamic & Primary & Ref. lab & X & Ref. lab \\
\hline
\end{tabular}

Mon. lab: monitoring laboratory

Ref. lab: Reference Laboratory

During normal operation the monitor usually loses sensitivity due to dirt buildup and electronic drift. This can be compensated by calibrating the monitor periodically and if necessary adjusting the monitor response. All monitors in the field are calibrated every three months at the station site using a travelling standard as reference. This does not apply to $\mathrm{O}_{3}$ monitors where there are no travelling standard. The $\mathrm{O}_{3}$ monitors are however known to be very stable.

Once a year every monitor in the network is brought to the Monitor lab and calibrated using the primary standard as reference. A dynamic or multipoint calibration is performed to verify the linearity of the monitor response. At the same time worn spare parts are changed.

\subsubsection{Calibration of Working Standards}

The working standard used at zero/span checks may change its concentration during its lifetime. Typically the gas concentration in cylinders will drop over time. This is not a problem as long as the span source is calibrated periodically. By periodically calibrating the working standard its certificate is renewed and the standard can be used after the producer's certificate has expired.

If the working standard is only a gas cylinder at ambient concentration it is always calibrated at the Reference lab when it is new. Other span sources such as high concentration gas cylinders which depend on dilution can not be calibrated at the lab. They must be calibrated at the station with the span source connected to the specific dilution unit it will use under normal operation. It is the output from that calibrator that must be calibrated.

The working standard is calibrated every three months at the station using a travelling standard as reference, Table 4. The calibration of the working standard is performed by first calibrating the monitor using the travelling standard as reference. Second the working standard is calibrated using the newly calibrated monitor.

Table 4: Calibration of working standards using a travelling standard as reference.

\begin{tabular}{llll}
\hline Working standard & Travelling & Period \\
\hline Unit & $\mathrm{Gas}$ & standard & \\
$\begin{array}{l}\text { Gas cylinder } \\
\text { w/dil. }\end{array}$ & $\mathrm{CO}, \mathrm{CH}_{4}+\mathrm{C}_{3} \mathrm{H}_{8}$ & $\mathrm{CO}, \mathrm{CH}_{4}+\mathrm{C}_{3} \mathrm{H}_{8}$ & 3 months \\
$\begin{array}{l}\text { Perm. tube } \\
\text { w/dil. }\end{array}$ & $\mathrm{NO}_{2}, \mathrm{SO}_{2}$ & $\mathrm{NO}, \mathrm{SO}_{2}$ & 3 months \\
Gas cylinder & $\mathrm{NO}, \mathrm{SO}_{2}$ & $\mathrm{NO}, \mathrm{SO}_{2}$ & 3 months \\
\hline
\end{tabular}

When the gas cylinder pressure is less then 15 bar the cylinder is considered empty. It should be returned to the lab for final calibration. The final calibration of high concentration gas cylinders must be performed at the site, while the cylinder is connected to the two point calibration unit.

There are no travelling standard for $\mathrm{O}_{3}$. 
Zero air for zero/span checks and zero level calibrations (Table 5) is produced by scrubbing ambient air. Table shows different scrubber materials and their calibration schedule.

Table 5: Check of zero air sources.

\begin{tabular}{llll}
\hline Scrubber & Removed gas & Monitor & Period \\
\hline Purafil & $\mathrm{NO} \quad \mathrm{NO}_{2}$ & $\mathrm{NO}_{\mathrm{x}}$ & 3 months \\
Activated charcoal & $\mathrm{NO}_{2}, \mathrm{SO}_{2}, \mathrm{O}_{3}$ & $\mathrm{NO}_{x}, \mathrm{SO}_{2}, \mathrm{O}_{3}$ & 3 months \\
Catalytic heater & $\mathrm{CO}, \mathrm{HC}$ & $\mathrm{CO}, \mathrm{HC}$ & 1 year \\
\hline
\end{tabular}

Purafil and activated charcoal is contained in canisters and are part of the zero/span check unit. The catalytic heater is a stand-alone instrument, which convert $\mathrm{CO}$ and $\mathrm{HC}$ to $\mathrm{CO}_{2}$ and water respectively.

The Purafil and activated charcoal scrubbers are checked by first recording the response on the monitor during the zero level check. Second the Purafil and activated charcoal canisters are changed with canisters filled with fresh scrubber material and the zero level check is repeated. If the two zero level readings on the monitor are not comparable the old scrubber material is changed.

It is not practical to check the zero level of the catalytic heater at the station. The catalytic heater is checked once a year in the lab during the yearly dynamic calibration of the monitor. The check is performed by first recording the response on the monitor during the zero level check. Second the catalytic converter is changed with the lab converter and the zero level check is repeated. If the two zero level readings on the monitor are not comparable the catalytic converter needs maintenance and may repair.

\subsubsection{Calibration of Travelling Standards}

Travelling standards are gas cylinders at ambient concentrations. The travelling and working standard gas cylinders are of the same type and quality. Both need periodical calibration.

The travelling standard is calibrated periodically in the lab using the primary standard as reference. The calibration of the travelling standard is performed by first calibrating a lab monitor using the primary standard as reference. Second the travelling standard is calibrated using the newly calibrated monitor. Table 6 shows the calibration schedule for travelling standard gas cylinders.

Table 6: Calibration of travelling standards using a primary standard as reference. All travelling and primary reference standards are gas cylinders

\begin{tabular}{lll}
\hline Travelling standard & Primary standard & Period \\
\hline $\mathrm{SO}_{2}$ & $\mathrm{SO}_{2}$ & 3 months \\
$\mathrm{NO}_{2}$ & $\mathrm{NO}_{2}$ & 3 months \\
$\mathrm{CO}$ & $\mathrm{CO}$ & 3 months \\
$\mathrm{CH}_{4}+\mathrm{C}_{3} \mathrm{H}_{8}$ & $\mathrm{CH}_{4}+\mathrm{C}_{3} \mathrm{H}_{8}$ & 3 months \\
\hline
\end{tabular}

Table shows typical concentrations for travelling gas standards. The concentration will depend upon the output concentration of the working standard at the site.

Table 7: Typical concentrations for travelling gas standards.

\begin{tabular}{lll}
\hline Cal. gas & Concentration & Cyl. vol. \\
\hline $\mathrm{SO}_{2}$ & $800 \mathrm{ppb}$ & 10 litre \\
$\mathrm{NO}$ & $800 \mathrm{ppb}$ & 10 litre \\
$\mathrm{CO}$ & $45 \mathrm{ppm}$ & 10 litre \\
$\mathrm{CH}_{4}+\mathrm{C}_{3} \mathrm{H}_{8}$ & $(1.8+0.2) \mathrm{ppm}$ & 10 litre \\
\hline
\end{tabular}

\subsubsection{Calibration of Primary Reference Standards}

The primary reference standard consists of a high concentration gas cylinder and a multipoint calibrator. In the monitoring network the traceable chain of calibrations ends here on the network level. In the Reference lab the traceable chain of calibrations ends here on the national level. All calibrations in the network depend on the quality of the primary reference gas standard and the calibrator's ability to dilute the gas correctly. Table shows typical concentrations of primary reference standards.

Table8:Typical primary reference gas standard concentrations. The gas is diluted in the multipoint calibrator using the indicated dilution ratio.

Table 8: primary reference gases dilution:

\begin{tabular}{lllll}
\hline Cal.gas & Concentration & Cylinder & Multipoint calibrator \\
\hline & & volume & Dilution & Output conc. \\
& $100 \mathrm{ppm}$ & 10 litre & $>1: 100$ & $<1 \mathrm{ppm}$ \\
$\mathrm{SO}_{2}$ & $100 \mathrm{ppm}$ & 10 litre & $>1: 100$ & $<1 \mathrm{ppm}$ \\
$\mathrm{NO}$ & $5000 \mathrm{ppm}$ & 10 litre & $>1: 100$ & $<50 \mathrm{ppm}$ \\
$\mathrm{CO}$ & $(180+20)$ & 10 litre & $>1: 100$ & $\begin{array}{l}<(1.8+0.2) \\
\mathrm{ppm}\end{array}$ \\
\hline
\end{tabular}

The primary reference standard for $\mathrm{O}_{3}$ monitors is an $\mathrm{O}_{3}$ generator with photometer. The $\mathrm{O}_{3}$ generated by the $\mathrm{O}_{3}$ generator is fed to both the photometer and to the $\mathrm{O}_{3}$ monitor being calibrated.

The photometer measures the generated $\mathrm{O}_{3}$. The calibration of $\mathrm{O}_{3}$ monitors depends on the photometer's ability to measure the generated $\mathrm{O}_{3}$ correctly.

\subsubsection{Calibration of Monitoring Lab Primary Reference Standards}

The Monitoring lab has reference standards for calibration of gas monitors except $\mathrm{O}_{3}$ monitors. $\mathrm{O}_{3}$ monitors are calibrated at the Reference lab.

Once a year, the multipoint calibrator is calibrated at the Reference lab. The calibration is performed by comparing the dilution ratios on the Reference lab and Monitoring lab calibrators. A lab monitor is subjected to a two point calibration using the Reference lab calibrator and primary 
gas standard as reference. The monitor response and calibrator dilution ratio are registered. The Reference lab primary gas standard and lab monitor is switched to the Monitoring lab calibrator. The dilution ratio which was used by the Reference lab calibrator during the span calibration is set on the Monitoring lab calibrator. The monitor response is once again registered. If the flow controllers of the two calibrators have equal calibration the monitor responses should be approximately equal. Table 9 shows the calibration schedule for Monitoring lab calibrator.

Primary reference standard gas cylinders are calibrated at the Reference lab when they are new and later once a year. Because of the yearly calibration the gas cylinder the cylinder can be used after the supplier's calibration certificate has expired. When the gas cylinder pressure goes below 15 bar the cylinder is considered empty. The near empty gas cylinder is calibrated at the Monitoring lab using a new primary standard gas cylinder as reference. Table 9 shows the calibration schedule for Monitoring lab primary reference gas standards.

Table 9: Calibration of monitoring lab primary reference standards

\begin{tabular}{|c|c|c|c|c|}
\hline \multirow[t]{2}{*}{ Span gas } & \multirow[t]{2}{*}{ Concentration } & \multirow{2}{*}{$\begin{array}{l}\text { Cylinder } \\
\text { volume }\end{array}$} & \multicolumn{2}{|c|}{ Single point-calibrator } \\
\hline & & & Dilution & $\begin{array}{l}\text { Output } \\
\text { conc. }\end{array}$ \\
\hline $\mathrm{SO}_{2}$ & $800 \mathrm{ppb}$ & 10 liter & $\mathrm{X}$ & $800 \mathrm{ppb}$ \\
\hline NO & $800 \mathrm{ppb}$ & 10 liter & $\mathrm{X}$ & $800 \mathrm{ppb}$ \\
\hline $\mathrm{CO}$ & $450 \mathrm{ppm}$ & 50 liter & $1: 10$ & $45 \mathrm{ppm}$ \\
\hline $\mathrm{CH}_{4}+\mathrm{C}_{3} \mathrm{H}_{8}$ & $(18+2) \mathrm{ppm}$ & 50 liter & $1: 10$ & $\begin{array}{l}(1.8+0.2) \\
\text { ppm }\end{array}$ \\
\hline $\mathrm{O}_{3}$ & $200 \mathrm{ppb}$ & $\mathrm{X}$ & $\mathrm{X}$ & $200 \mathrm{ppb}$ \\
\hline
\end{tabular}

A primary reference standard gas cylinder contains high concentration gas which must be diluted in the calibrator before it is fed to the monitor. The cylinder is calibrated by first calibrating a lab monitor using a valid gas primary gas standard and the multipoint calibrator as reference. Second the gas cylinder being calibrated is connected to the calibrator and while using the same dilution ratio the monitor response is registered.

\subsubsection{Calibration of Reference Lab Primary Reference Standards}

Biannually the multipoint calibrator is calibrated abroad. It is the flow controllers that are calibrated. The $\mathrm{O}_{3}$ photometer of the $\mathrm{O}_{3}$ calibrator is calibrated abroad biannually.Table 10 shows the calibration schedule for Reference lab primary standard calibrators.

Table 10: Calibration of Reference lab primary standard calibrators.

\begin{tabular}{llc}
\hline Calibrator & Location & Period \\
\hline Multipoint calibrator & Abroad & 2 years \\
$\mathrm{O}_{3}$ photometer & Abroad & 2 years \\
\hline
\end{tabular}

The primary reference standard gas cylinders at the
Reference lab are never used after the calibration certificate of the gas cylinder producer has expired. When the gas cylinder pressure goes below 15 bar the cylinder is considered empty. In both cases the gas cylinder is calibrated at the Reference lab using a new primary standard gas cylinder as reference. Table 11 shows the calibration schedule for Reference lab primary reference gas standards.

Table 11: Calibration of Reference lab primary reference standard gas cylinders

\begin{tabular}{llll}
\hline Calibrated & Reference & Location & Period \\
\hline Item & standard & & \\
Multipoint cal. & Multipoint cal. & Ref. lab & 1 year \\
Gas cylinder & Valid cylinder & Ref. lab & Cylinder is new \\
Gas cylinder & Valid cylinder & Ref. lab & 1 year \\
Gas cylinder & New cylinder & Mon. lab & Cylinder is empty \\
\hline
\end{tabular}

A primary reference standard gas cylinder contains high concentration gas which must be diluted in the calibrator before it is fed to the monitor. The cylinder is calibrated by first calibrating a lab monitor using a valid gas primary gas standard and the multipoint calibrator as reference. Second the gas cylinder being calibrated is connected to the calibrator and while using the same dilution ratio the monitor response is registered.

\section{Conclusion}

It must be constructed a calibration traceability system in the Air monitoring systems in order to conform good Monitoring Practices.

Rigorous and comprehensive quality programs are implemented to ensure that data collected is complete, representative, accurate and defensible. Our Quality Assurance Program is comprised of the following components

- Automated weekly zero and single point span calibration as well as quarterly multi-point calibrations for continuous monitoring stations.

- Bi-annually external multi-point calibration is recommended.

\section{References}

[1] Rudolf Brázdil, Documentary Evidence of an Economic Character as a Source for the Study of Meteorological and Hydrological Extremes and their Impacts on Human Activities, geografiskaannaler series A:Physical geography, Issue 22006

[2] National Air Pollution Surveillance NetworkQuality Assurance and Quality Control Guidelines, Environment Canada - Environmental Technology Centre, Report No. AAQD $2004-1,2004$ 
[3] Michael L. Stein, Statistical methods for regular monitoring data, Journalof the royal statistical society: series B (statistical methodology), Issue 52005

[4] Simo, K. Haslett, metrological Tsunamis in southern Britain: an historical review geographical review, Issue 22009

[5] EPA 1996, Environmental Protection Agency Volunteer Monitor's Guide to: Quality Assurance Project Plans. 1996.

[6] Water, Land and Air Protection. Residential Wood Burning Emissions in British Columbia; the British Columbia Ministry of Water, Land and Air Protection. 2000; available at

http://www.env.gov.bc.ca/air/airquality/pdfs/wood_emission s.pdf (accessed 2006).

[7] National Emissions Inventory and Projections Task Group. 1995 Criteria Air Contaminants Emissions Inventory Guidebook; National Emissions Inventory and Projections Task Group. Canadian Council of Ministers of the Environment: Ottawa, Canada, 2000.

[8] Setton, E.; Hystad, P.; Keller, P. Opportunities for Using Spatial Property Assessment Data in Air Pollution Exposure Assessments; Int.J. Health Geographics2005
[9] EPA 841-B-96-003, Sep 1996, U.S. EPA, Office of Wetlands, Washington, D.C. 20460, USA

[10] MieczyslawSzyszkowicz, Air Pollution and Daily Emergency Department Visits for Headache in Montreal, Canada, HEADACHE, Issue 32008

[11] Sue Kimbrough, Richard W. Baldauf\&Nealson Watkins, Seasonal and diurnal analysis of NO2 concentrations from a long-duration study conducted in Las Vegas, Nevada, Journal of the Air \& Waste Management Association, 2013, Article Views: 47

[12] Charles L. Blanchard\&George M. Hidy, Effects of Changes in Sulfate, Ammonia, and Nitric Acid on Particulate Nitrate Concentrations in the Southeastern United States, Journal of the Air \& Waste Management Association, article view 50, 2012 .

[13] Kanaroglou, P.S.; Jerrett, M.; Morrison, C.; Beckerman, B.; Arainb, M.A.; Gilbertd, N.L.; Brooke, J.R. Establishing an Air Pollution Monitoring Network for Intra-Urban Population Exposure Assessment: a Location-Allocation Approach; Atmos. Environ.2005 